\title{
Effect of biodegradable versus nondegradable nasal packings in the outcome of functional endoscopic sinus surgery: clinical and histopathological study
} Ayman Al-Madani $^{a}$, Ahmed Youssef $^{a}$, Ayman Abduljalil ${ }^{a}$, Hoda Khalifa ${ }^{b}$, Mohamed Zahran ${ }^{a}$

Departments of a Otolaryngology and Head and

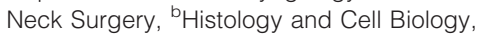
Alexandria University, Alexandria, Egypt

Correspondence to Ahmed Youssef, MD, PhD, MRCS, Department of Otolaryngology and Head and Neck Surgery, Faculty of Medicine, Alexandria University, 8 Elgesh St, Elazareeta, Alexandria University, Alexandria, 21131, Egypt.

Tel: +20 111000 3881/+44 70824431 955; e-mails: ahmedyouseef2002@yahoo.com, ahmed.youssef@nhs.net

Received 19 February 2018

Accepted 24 May 2018

The Egyptian Journal of Otolaryngology 2018, 34:253-265

\begin{abstract}
Background
Nasal packing has been used to prevent bleeding and formation of adhesions between the middle turbinate and lateral nasal wall. There has been a debate whether biodegradable packing might improve the outcome, or could a nondegradable dressing offer a better course after endoscopic sinus surgery.

Objective

To compare the effect of biodegradable versus nondegradable nasal packings on the outcome of endoscopic sinus surgery on clinical, endoscopic, and histopathologic basis.

Patients and methods

Fifty patients with bilateral chronic rhinosinusitis of the same extent of sinus affection were enrolled in this study. None of them was a revision case. All patients had bilateral functional endoscopic sinus surgery by the same surgeon using the same technique of powered microdebrider utilization. At the end of the procedure, the operative cavity of each patient was randomly packed with Merocel as a nondegradable material on one side and a biodegradable material on the other side. We assessed the patients regarding immediate postoperative symptoms and endoscopic follow-up after 1- and 3-month postoperatively including biopsy taking for histopathological examination.

Results

Postoperative bleeding and patient discomfort were significantly higher in the nondegradable packing side, while biodegradable packing has caused significantly more edema. Merocel packed sides showed better epithelial restoration with marked epithelial hyperplastic changes and more goblet cells than the biodegradable sides. This difference was statistically significant 1 month postoperatively, but turned nonsignificant 3-month postoperatively.

\section{Conclusions}

Biodegradable nasal packing can offer patients a good quality of life during the early recovery period without beneficial or detrimental effects on postoperative mucosal healing. Nondegradable packs offer less post-functional endoscopic sinus surgery edema providing better aeration and rapid wound healing.
\end{abstract}

\section{Keywords:}

biodegradable, chronic rhinosinusitis, endoscopic sinus surgery, nondegradable, postoperative

Egypt J Otolaryngol 34:253-265

( 2018 The Egyptian Journal of Otolaryngology

1012-5574

\section{Introduction}

The role of endoscopic sinus surgery (ESS) for medical refractory chronic rhinosinusitis (CRS) is well established in providing symptomatic relief and improvements in quality of life [1]. Postoperative wound healing plays a critical role in producing a successful result after functional endoscopic sinus surgery (FESS). The degree of inflammation within the middle meatus is critical and can influence scar tissue formation and therefore synechiae, which tend to occur between the middle turbinate and lateral nasal wall. Despite advancements in technology and training, the formation of synechiae continues to remain one of the most common causes of surgical failure in FESS, with an incidence of up to 27\% [2].

Various surgical techniques, including mucosal sparing techniques, middle turbinate resection or medialization, and frequent postoperative debridement have been used to prevent postoperative synechiae [3]. When synechia occur in the middle meatus, the maxillary, ethmoid, and

This is an open access journal, and articles are distributed under the terms of the Creative Commons Attribution-NonCommercial-ShareAlike 4.0 License, which allows others to remix, tweak, and build upon the work non-commercially, as long as appropriate credit is given and the new creations are licensed under the identical terms. 
frontal sinuses may become obstructed resulting in recurrent problems [4].

To minimize inflammation and formation of scar tissue, sinus surgeons have used various types of nasal packing between the middle turbinate and lateral nasal wall [2]. Nasal packing has been the traditional method of controlling ongoing bleeding after surgery to the paranasal sinuses [5]. Additionally, nasal packing has been used to prevent adhesion formation between the middle turbinate and lateral nasal wall, floppiness of the middle turbinate attachment, middle turbinate lateralization, and restenosis after surgery [6].

Recently, absorbable biomaterials have become available for intranasal packing [7]. Absorbable biomaterials are commonly used after FESS, both for hemostatic and wound-healing considerations. Although removable nasal packing is the traditional method of controlling ongoing bleeding and modulating wound healing, it is uncomfortable for patients and is associated with several complications [6].

There is a debate whether biodegradable packing might improve the outcome or could a nondegradable dressing offer a better course after FESS. The present work aims at assessing the differences between biodegradable and nondegradable nasal packing with regard to their effects on postoperative symptoms, endoscopic findings, and tissue healing after FESS.

\section{Patients and methods}

The study was conducted at the Department of Otolaryngology and Head and Neck Surgery, University of Alexandria, on 50 patients undergoing bilateral ESS for medical refractory primary or recurrent CRS with polyposis. All operations were done by the same surgeon using a powered microdebrider. The extent of the pathology was almost the same on both sides for each patient. Approval of the Ethics Committee in Faculty of Medicine, Alexandria University, was taken before conduction of the study. Informed consent was taken from all the patients in the study.

Patients with known hypersensitivity to any of absorbable packing materials or underlying immunological or coagulation problems are excluded. Recurrent cases where middle turbinate was resected in primary surgery were excluded as well.

\section{Study design}

A randomized, controlled clinical trial was conducted, in which the selected patients were randomly assigned to five groups:

(1) Gelfoam group: patients packed with biodegradable nasal packing (Gelfoam) on one side and nondegradable nasal packing (Merocel) on the other side at the completion of the operation.

(2) Surgicel group: patients packed with biodegradable nasal packing (Surgicel) on one side and nondegradable nasal packing (Merocel) on the other side at the completion of the operation.

(3) Nasopore group: patients packed with biodegradable nasal packing (Nasopore) on one side and nondegradable nasal packing (Merocel) on the other side at the completion of the operation.

(4) Surgiflo group: patients packed with biodegradable nasal packing (Surgiflo) on one side and nondegradable nasal packing (Merocel) on the other side at the completion of the operation.

(5) Sinu-Foam group: patients packed with biodegradable nasal packing (Stammberger's SinuFoam) on one side and nondegradable nasal packing (Merocel) on the other side at the completion of the operation.

Postoperative care was performed for all patients that included weekly debridement, antibiotics, steroids, and nasal douching as well.

Assessment of the outcome was based on the following in all patients:

(1) Subjective assessment

This involved assessment of postoperative discomfort and blood loss. Nasal obstruction, facial pain, headache, and disturbance of smell were assessed according to the visual analog scale for nasal symptoms. All patients were asked to rate their symptoms on a visual analog scale of $0-10$, where ' 0 ' means no symptoms are present; ' 10 ' means the most severe symptom.

(2) Objective assessment

\section{(a) Endoscopic assessment}

The patients were evaluated endoscopically after surgery at 1 and 3 months. The operative cavity was evaluated for the presence of polypi, presence of synechia (obstructing or nonobstructing), presence of crusts (mild, moderate, and obstructing), appearance of secretions (normal, thin-clear, and thick-purulent), appearance of mucosa 
(normal, mild edema, and severe edema), and the presence of granulation tissue (absent, islands, marked).

(b) Histopathological assessment

Tissue biopsies were taken during endoscopic examination at 1 - and 3-month visits for histopathological study. Biopsies were taken from the operative cavity postFESS using thru-cut forceps and Blakesley forceps under local anesthesia. Slides were stained with hematoxylin and eosin for histopathological assessment for the following parameters.

(1) Epithelial layer:

Restoration of epithelium: complete incomplete.

Epithelial thickness: normalhyperplastic-atrophic.

Epithelial metaplasia: present-absent.

Goblet cells: scanty-abundant.

Basement membrane thickness: normalmild-marked.

(2) Subepithelial layer:

Inflammatory cell population: mean $\pm \mathrm{SD}$.

Foreign body giant cells: absent-present.

(3) Stroma layer:

Glandular activity: limited-marked.

Newly formed blood vessels: mildmarked.

Edema: no-mild-marked.

\section{Results}

The statistical analysis of preoperative computed tomographic (CT) scans showed no statistically significant difference between the biodegradable and nondegradable sides regarding the Lund Mackay score for CT staging $(P=0.674)$ and Lund Kennedy score for sinus disease $(P=0.256)$. CT and endoscopic scores of the studied patients is summarized in Table 1 .

Both nasal sides of all involved patients mostly had the same extent of surgical intervention except for some differences regarding the sphenoid and frontal recess surgery which were statistically not significant $(P>0.05)$ (Table 2).
Postoperative oozing of blood was significantly higher in nondegradable sides than in the biodegradable sides (Fig. 1). However, the patients' discomfort due to sense of nasal obstruction was much more in the Merocel sides than the biodegradable sides (Fig. 2). Regular follow-up of the cases involved in this study regarding postoperative synechia showed no statistically significant difference between the nondegradable and biodegradable sides at 1- and 3-month, postoperatively (Figs 3, 4). Despite good medical treatment, a very limited number of cases showed reformation of polypoid tissue inside the operative cavity at the 1month postoperative visit (three cases on each side). This number increased slightly (four cases) regarding the nondegradable sides and increased markedly (10 cases) regarding the biodegradable sides at the 3month postoperative visit. However, this difference between the biodegradable and nondegradable sides throughout both visits was not statistically significant. Also, cases involved in this study were followed up regularly to study the effect of the type of packing material on granulation tissue formation postoperatively. Statistically, no significant difference was found between the biodegradable and nondegradable sides regarding the granulation tissue formation (Table 3).

The crust formation in the operative cavity postoperatively is noticed in the biodegradable packed sides more than the nondegradable sides. Statistical analysis of this finding showed significant difference between the biodegradable and nondegradable sides at 1 - and 3-month visits (Figs $5,6)$. The edema of mucosal lining in the operative cavity was evident much more in the biodegradable sides than the nondegradable sides. Statistically, the difference was significant at the 1- and 3-month postoperative visits (Figs 7, 8).

Histopathological examination of nasal biopsies was done taking into consideration the individual variation. The right nondegradable (Merocel) packed side biopsy was compared with the left biodegradable packed side biopsy for each patient. By follow-up of the taken biopsies for inflammatory cellular infiltration, no statistically significant difference was found between

Table 1 Comparison between nondegradable and biodegradable sides regarding the Lund Mackay score for computed tomography staging; Lund Kennedy score for sinus disease

\begin{tabular}{lccc}
\hline & $\begin{array}{c}\text { Nondegradable side }(N=50) \\
(\text { mean } \pm \text { SD })\end{array}$ & $\begin{array}{c}\text { Biodegradable side }(N=50) \\
(\text { mean } \pm \text { SD })\end{array}$ & $\begin{array}{c}\text { Mann-Whitney } U \text { test } \\
P \text { value }\end{array}$ \\
\hline Lund Mackay score for CT staging & $9.52 \pm 1.61$ & $9.38 \pm 1.71$ & $U=1190.000 P=0.674$ \\
Lund Kennedy score for sinus disease & $2.06 \pm 0.712$ & $2.22 \pm 0.708$ & $U=1198.500 P=0.256$ \\
\hline
\end{tabular}

CT, computed tomography. 
Table 2 Comparison between nondegradable and biodegradable sides regarding the extent of functional endoscopic sinus surgery

\begin{tabular}{|c|c|c|c|}
\hline & $\begin{array}{c}\text { Nondegradable } \\
\text { side }[N(\%)]\end{array}$ & $\begin{array}{c}\text { Biodegradable } \\
\text { side }[N(\%)]\end{array}$ & $\begin{array}{l}\chi^{2} \text { test } \\
P \text { value }\end{array}$ \\
\hline \multicolumn{4}{|c|}{ Uncinectomy } \\
\hline Yes & $50(100)$ & $50(100)$ & - \\
\hline No & 0 & 0 & \\
\hline \multicolumn{4}{|c|}{ Antrostomy } \\
\hline Yes & $50(100)$ & $50(100)$ & - \\
\hline No & 0 & 0 & \\
\hline \multicolumn{4}{|c|}{ Anterior ethmoidectomy } \\
\hline Yes & $50(100)$ & $50(100)$ & - \\
\hline No & 0 & 0 & \\
\hline \multicolumn{4}{|c|}{ Posterior ethmoidectomy } \\
\hline Yes & $50(100)$ & $50(100)$ & - \\
\hline No & 0 & 0 & \\
\hline \multicolumn{4}{|c|}{ Sphenoidotomy } \\
\hline Yes & $48(96)$ & $47(94)$ & $\begin{array}{c}=0.211 \\
0.646\end{array}$ \\
\hline No & $2(4)$ & $3(6)$ & \\
\hline \multicolumn{4}{|c|}{ Frontal recess surgery } \\
\hline Yes & $45(90)$ & $45(90)$ & - \\
\hline No & $5(10)$ & $5(10)$ & \\
\hline
\end{tabular}

\section{Figure 1}

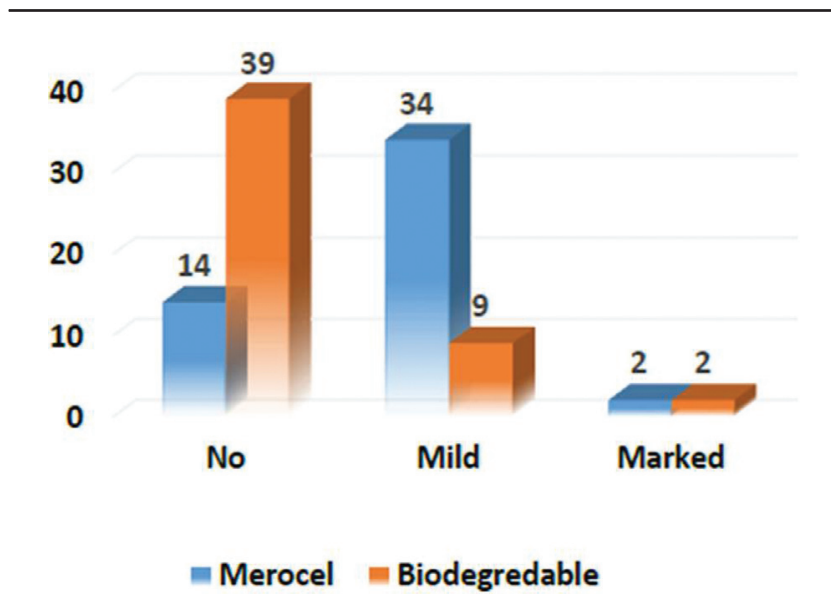

Bar chart illustrating postoperative blood loss while the packing in place.

biodegradable and nondegradable packing sides regarding the inflammatory cellular population at 1 month postoperatively, but it turned significant at 3month postoperative specimens (Table 4). Better epithelial restoration with marked epithelial hyperplastic changes and more goblet cell were seen in the Merocel sides than the biodegradable sides. This difference was statistically significant 1-month postoperatively, but turned nonsignificant at 3-month postoperatively. Basement membrane thickness showed no statistically significant difference between the biodegradable and nondegradable sides. No signs of epithelial hyperplasia were seen neither in biodegradable nor in nondegradable sides.
Figure 2

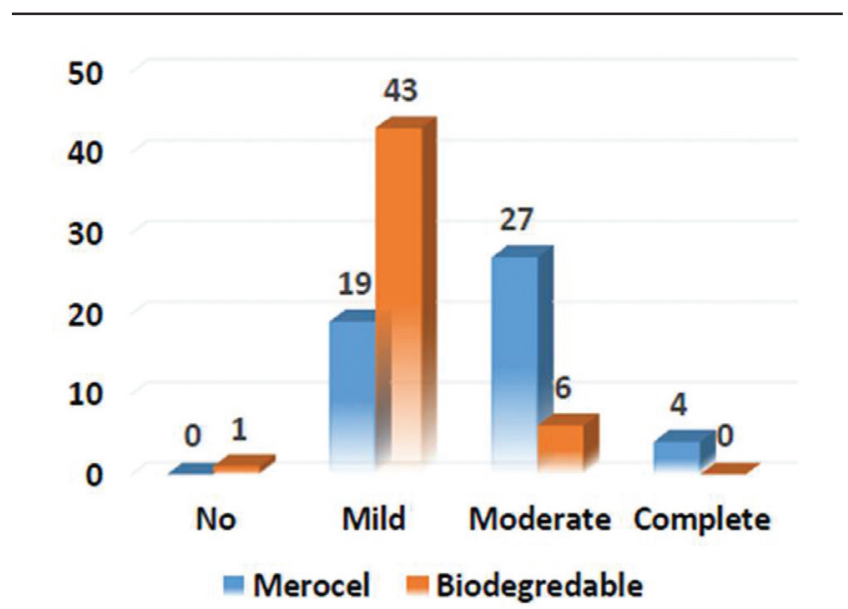

Bar chart illustrating postoperative nasal obstruction while the packing in place.

By assessing the condition of stroma of the sinonasal mucosa, edema was significantly more evident in the biodegradable sides than the nondegradable sides both at 1- and at 3-month postoperatively. Regarding the subepithelial glandular activity, despite more activity seen in the nondegradable sides, no statistically significant difference was found between the biodegradable and nondegradable sides at 1- and 3-month postoperatively. The formation of new blood vessels was significantly more in the biodegradable than the nondegradable sides at 1month postoperatively, but it turned nonsignificant at 3-month postoperatively. No foreign body giant cells were noted in neither biodegradable nor nondegradable sides at 1 - and 3-month postoperatively (Figs 9-14).

\section{Discussion}

Nasal packing was first described in the otorhinolaryngologic literature in 1951[8], and since then it has been designed to repress mucosal bleeding and improve wound healing, postoperatively. Unfortunately, pain upon its removal has been described by patients as the most unpleasant aspect of the surgical experience [9] and it can increase postoperative morbidity including infection and sleep-disordered breathing [10] and so on. The innovations in nasal packing were motivated by the innate defects of conventional packings (ribbon gauze and Merocel) in the quality of life during early postoperative period. Also, they were expected to improve mucosal healing. Emerging biodegradable materials have put authors in a great debate about which type of nasal packing, whether biodegradable or not, has a better impact on subjective and objective outcomes of FESS [11]. 
Figure 3

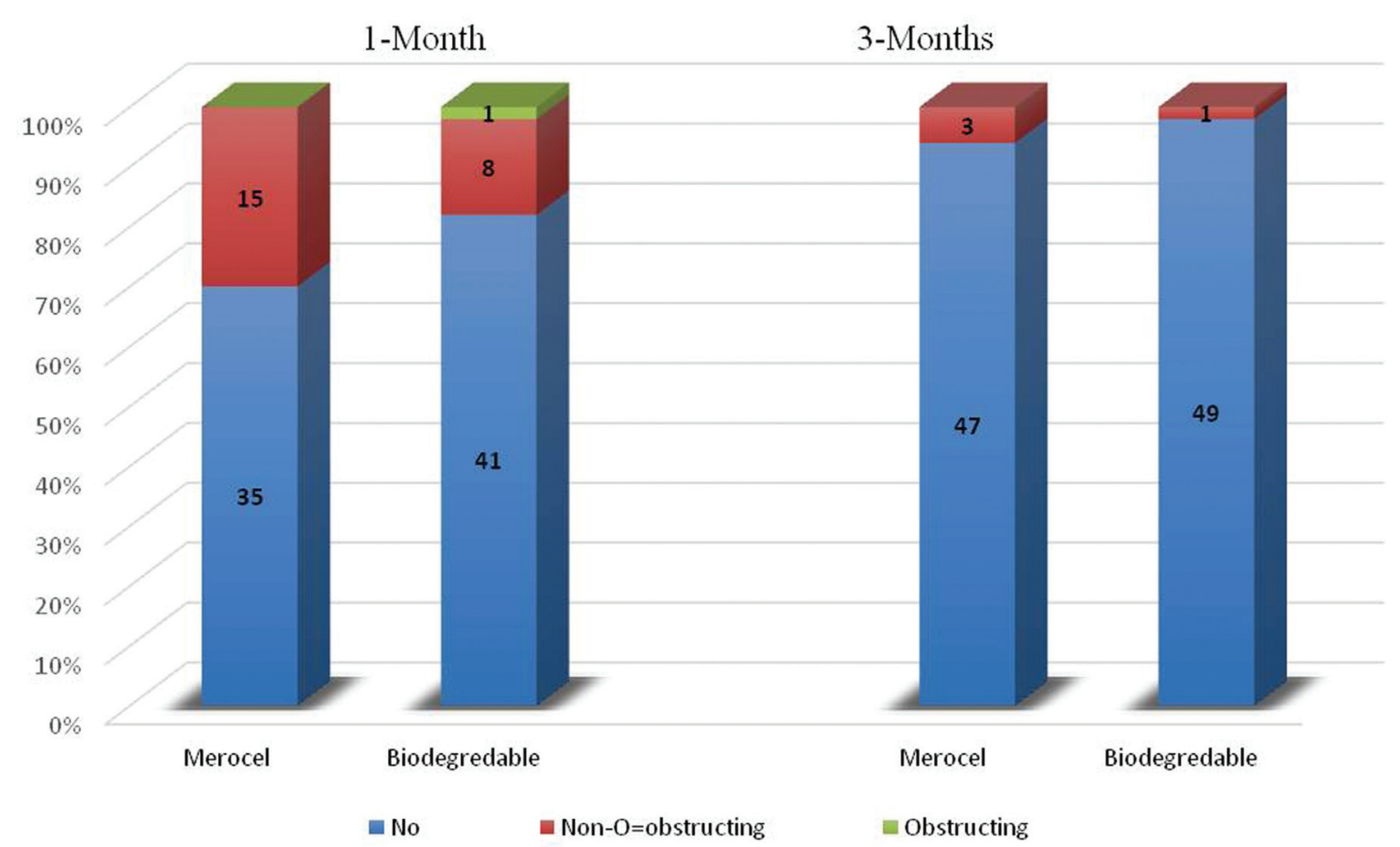

Bar chart illustrating synechia formation at 1- and 3-month postoperatively.

Figure 4
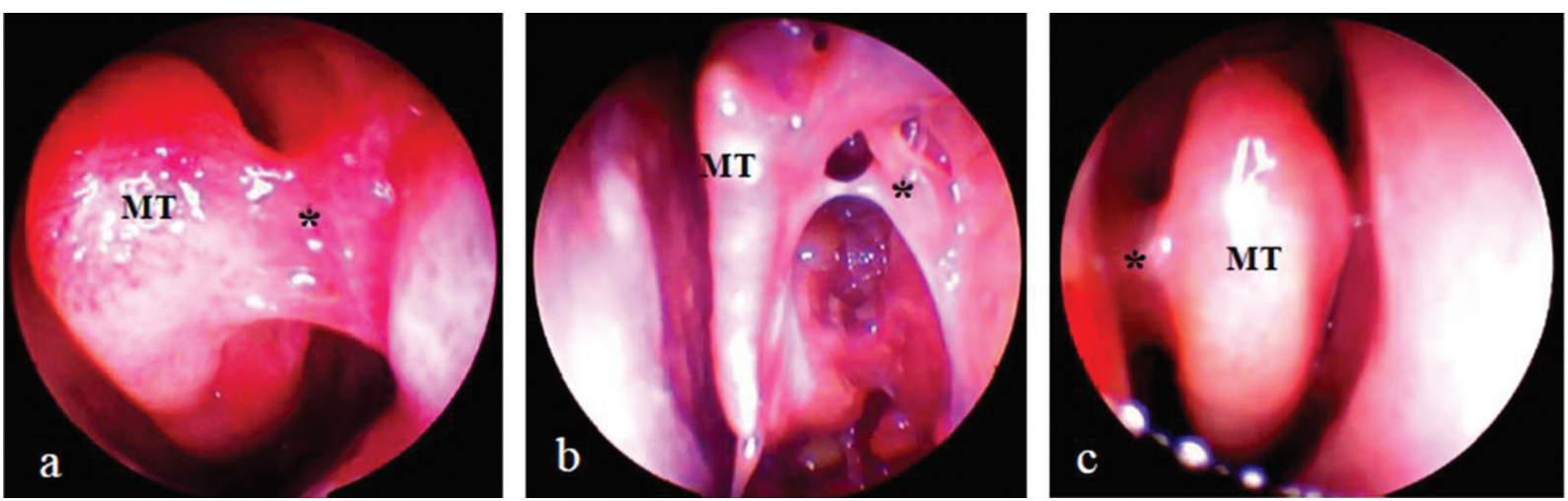

Nasal endoscopy showing: (a) nonobstructing synechia $\left(^{*}\right) 1$-month postoperatively in Gelfoam packed on the left side. (b) Nonobstructing synechia $\left(^{*}\right)$ in Surgicel packed on the left side 1-month postoperatively. (c) Obstructing synechia $\left(^{*}\right)$ in Merocel packed on the right side 1-month postoperatively.

Table 3 Comparison between biodegradable and nondegradable sides regarding the granulation tissue formation at 1- and 3month postoperatively

\begin{tabular}{lccccccc}
\hline & \multicolumn{3}{c}{1 month $[n(\%)]$} & & 3 months $[n(\%)]$ \\
\cline { 2 - 3 } & $\begin{array}{c}\text { Merocel } \\
(N=50)\end{array}$ & $\begin{array}{c}\text { Biodegradable } \\
(N=50)\end{array}$ & $\begin{array}{c}\chi^{2} \text { test exact } P \\
\text { value }\end{array}$ & & $\begin{array}{c}\text { Merocel } \\
(N=50)\end{array}$ & $\begin{array}{c}\text { Biodegradable } \\
(N=50)\end{array}$ & $\begin{array}{c}\chi^{2} \text { test exact } P \\
\text { value }\end{array}$ \\
\hline Granulations & & & & & & \\
No & $27(54)$ & $31(62)$ & 2.6750 .293 & & $42(84)$ & $38(76)$ & 2.4220 .397 \\
Islands & $19(38)$ & $12(24)$ & & & $8(16)$ & $10(20)$ & \\
Marked & $4(8)$ & $7(14)$ & & & 0 & $2(4)$ & \\
\hline
\end{tabular}

Almost all studies have evaluated the effect of packing on symptomatic and/or endoscopic basis. Some studies have assessed the histopathological effect of packing in animal models using the sheep model to study nondegradable packing [12] and biodegradable packing [13]. In the current study, we have compared the biodegradable materials (Gelfoam, Surgicel, Nasopore, Stammberger's Sinu-Foam, and 
Figure 5

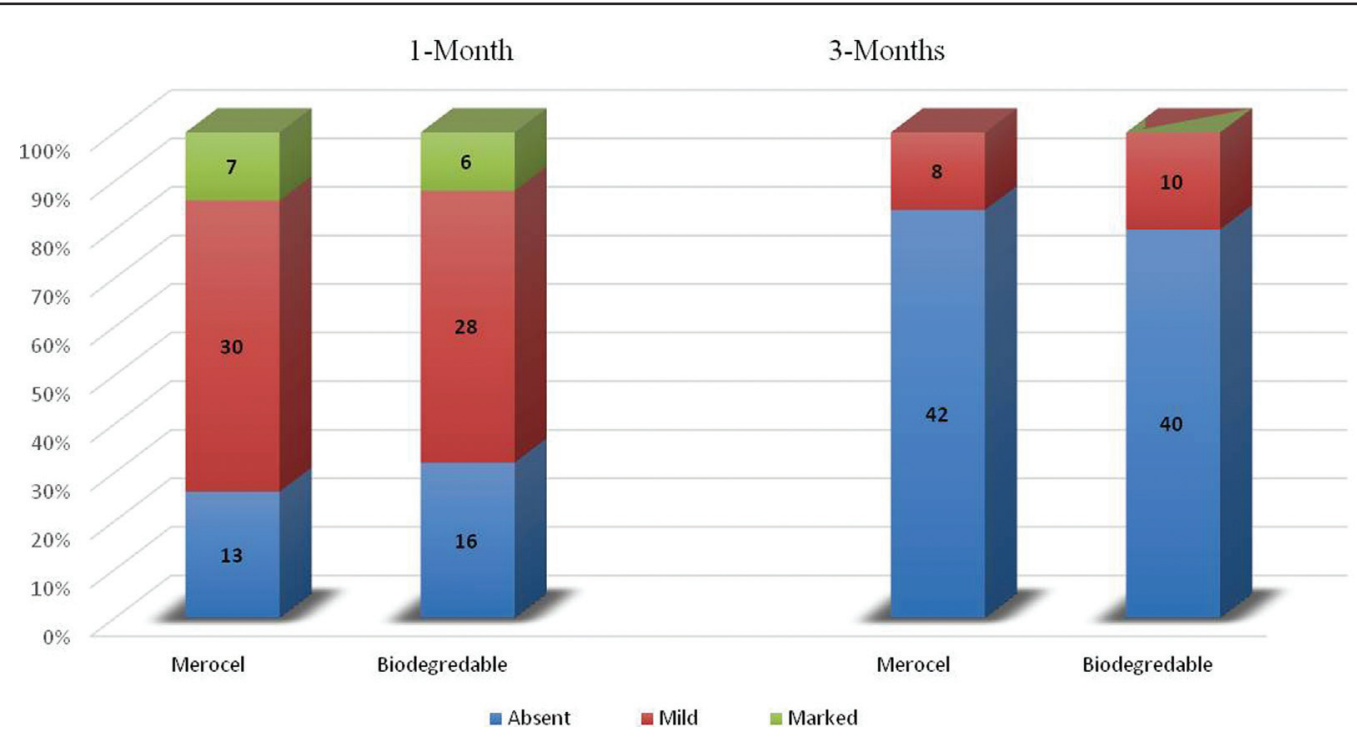

Bar chart illustrating crust formation at 1- and 3-month postoperatively.

\section{Figure 6}
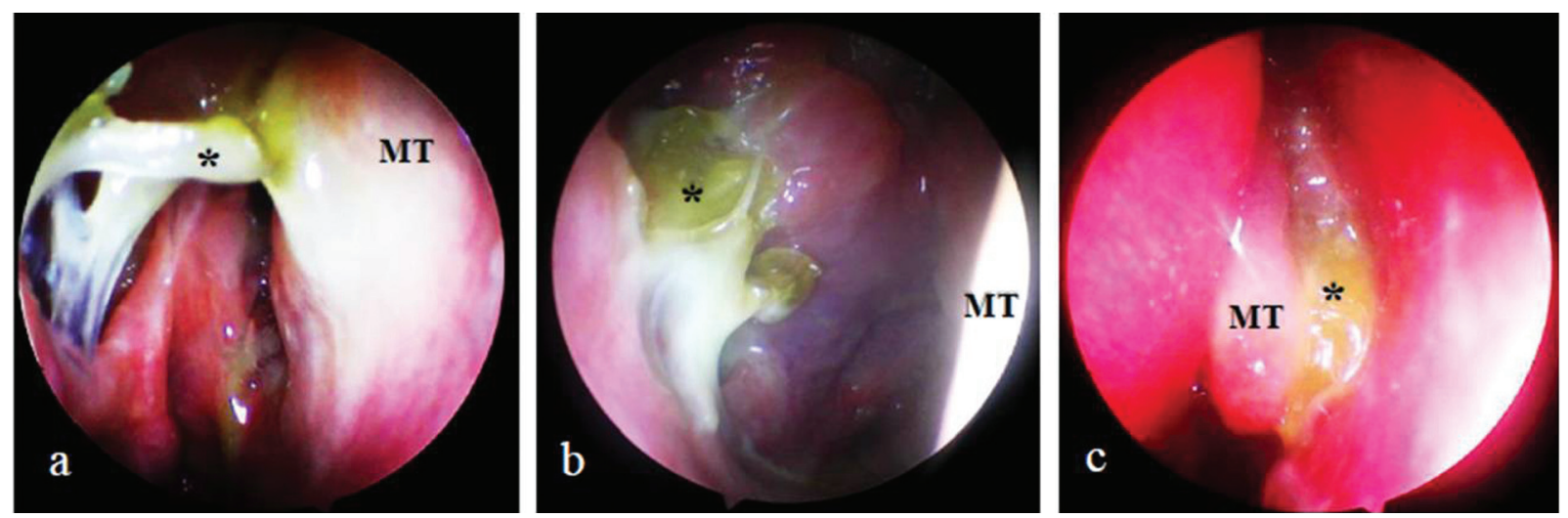

Nasal endoscopy showing: (a) Crustations* mildly obstructing the maxillary antrostomy in Merocel packed on the right side 2-month postoperatively. (b) Mild crusts in Merocel packed on the right side 1-month postoperatively. (c) Marked crust formation obliterating the middle meatus in Gelfoam packed on the left side 1-month postoperatively. MT, middle turbinate.

\section{Figure 7}

1-Month

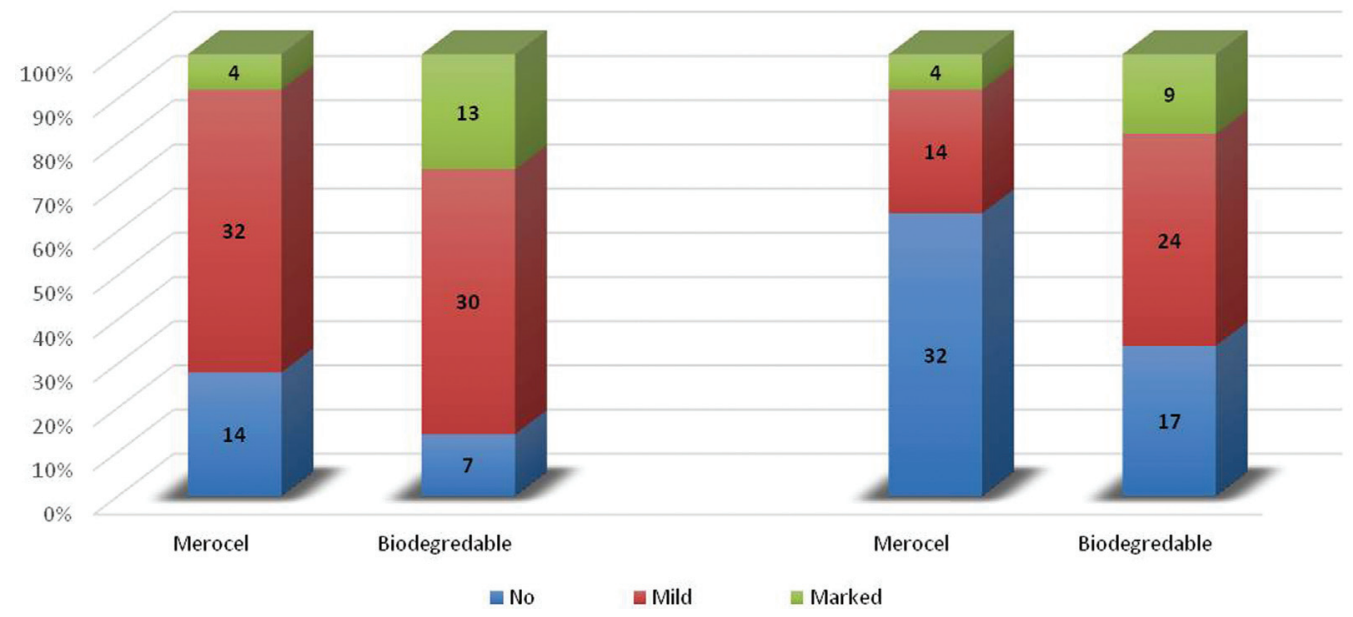

Bar chart illustrating mucosal edema at 1- and 3-month postoperatively. 
Figure 8
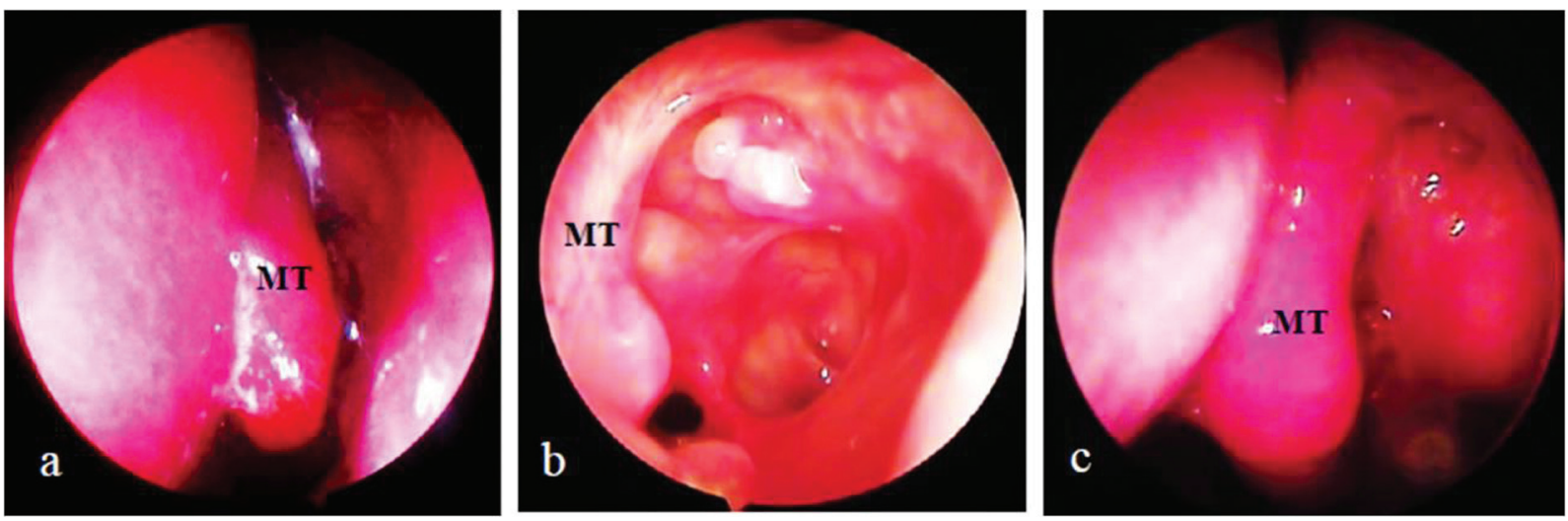

Nasal endoscopy showing: (a) Marked mucosal edema in Gelfoam packed on the left side 1-month postoperatively. (b) Mild mucosal edema in Stammberger's Sinu-Foam packed on the left side 1-month postoperatively. (c) Marked mucosal edema obliterating the middle meatus in Surgiflo packed on the left side 3-month postoperatively.

Table 4 Comparison between biodegradable and nondegradable sides regarding the inflammatory cellular infiltration at 1- and 3month postoperatively

\begin{tabular}{|c|c|c|c|c|c|c|}
\hline & \multicolumn{3}{|c|}{ 1-month visit $($ mean $\pm S D)$} & \multicolumn{3}{|c|}{ 3-month visit (mean $\pm S D)$} \\
\hline & Merocel & Biodegradable & $\begin{array}{l}\text { Mann-Whitney } \\
U \text { test } P \text { value }\end{array}$ & Merocel & Biodegradable & $\begin{array}{l}\text { Mann-Whitney } \\
U \text { test } P \text { value }\end{array}$ \\
\hline Inflammatory cells population & $63.66 \pm 24.92$ & $75.22 \pm 29.13$ & 1002.5000 .088 & $110.16 \pm 43.27$ & $131.68 \pm 45.09$ & $951.000 P<0.039$ \\
\hline
\end{tabular}

Figure 9
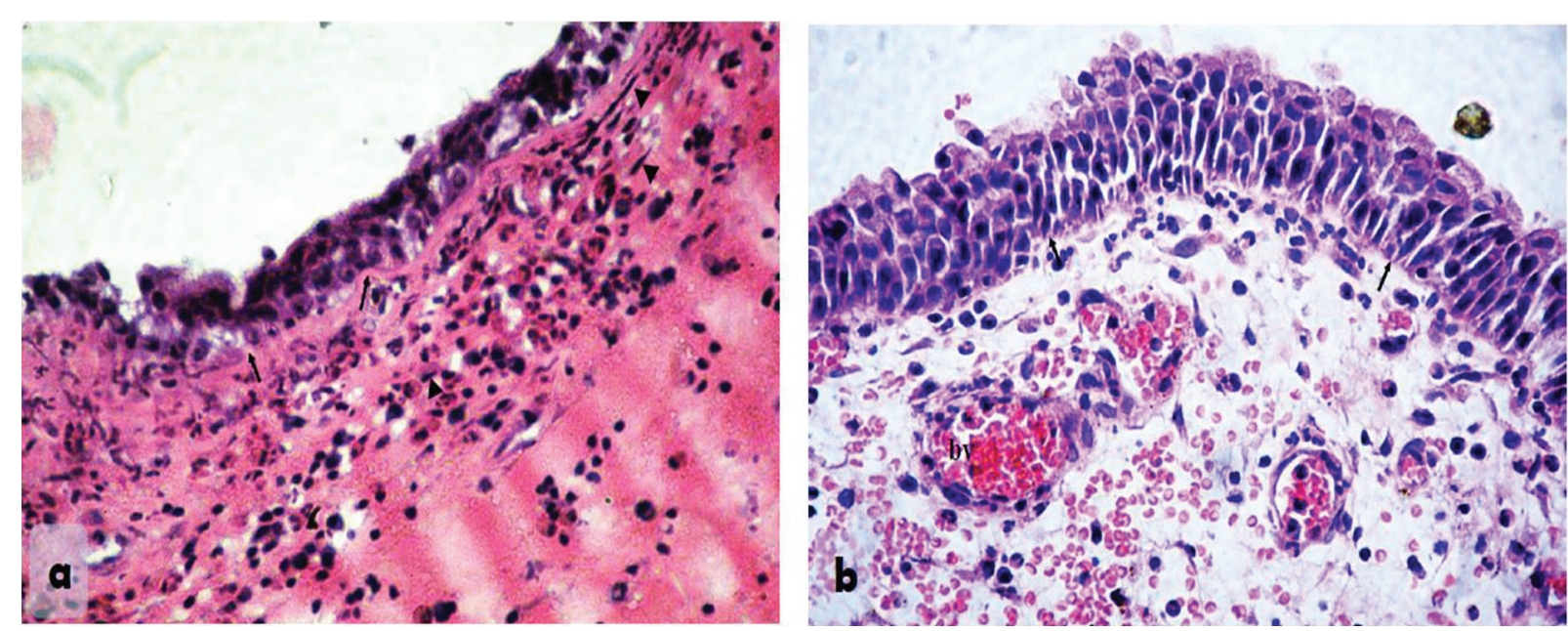

One-month postoperatively case shows (a) Merocel packed side showing pseudostratified columnar epithelium with goblet cells resting on thickened basement membrane $(\uparrow)$. The lamina propria shows excessive fibroblastic activity (?) with mononuclear cellular infiltration. (b) Gelfoam packed side showing mild cellular hyperplasia resting on thin basement membrane $(\uparrow)$. The lamina propria shows edema with congested blood vessels (bv) and extravasated red blood cells. Hematoxylin and eosin stain Mic. magnification, $\times 400$.

Surgiflo) with the Merocel regarding postoperative symptoms, endoscopic, and histopathological effect.

The present study included 50 patients with CRS indicated for FESS. Out of the 50 patients, 27 (54\%) were men and $23(46 \%)$ were women. The mean age of the patients was $33.60 \pm 10.11$ years with a range of $16-58$ years. One of the positive points supporting the current study is the homogeneity between the two packing sides with no significant difference between them regarding the Lund Mackay score for preoperative CT scanning of nose and paranasal sinuses. All cases were done by the same surgeon using the same powered instrumentation and the same technique for endoscopic surgery. This ascertains the presence of similar preoperative and operative conditions in the two packing sides making the results more valid. 

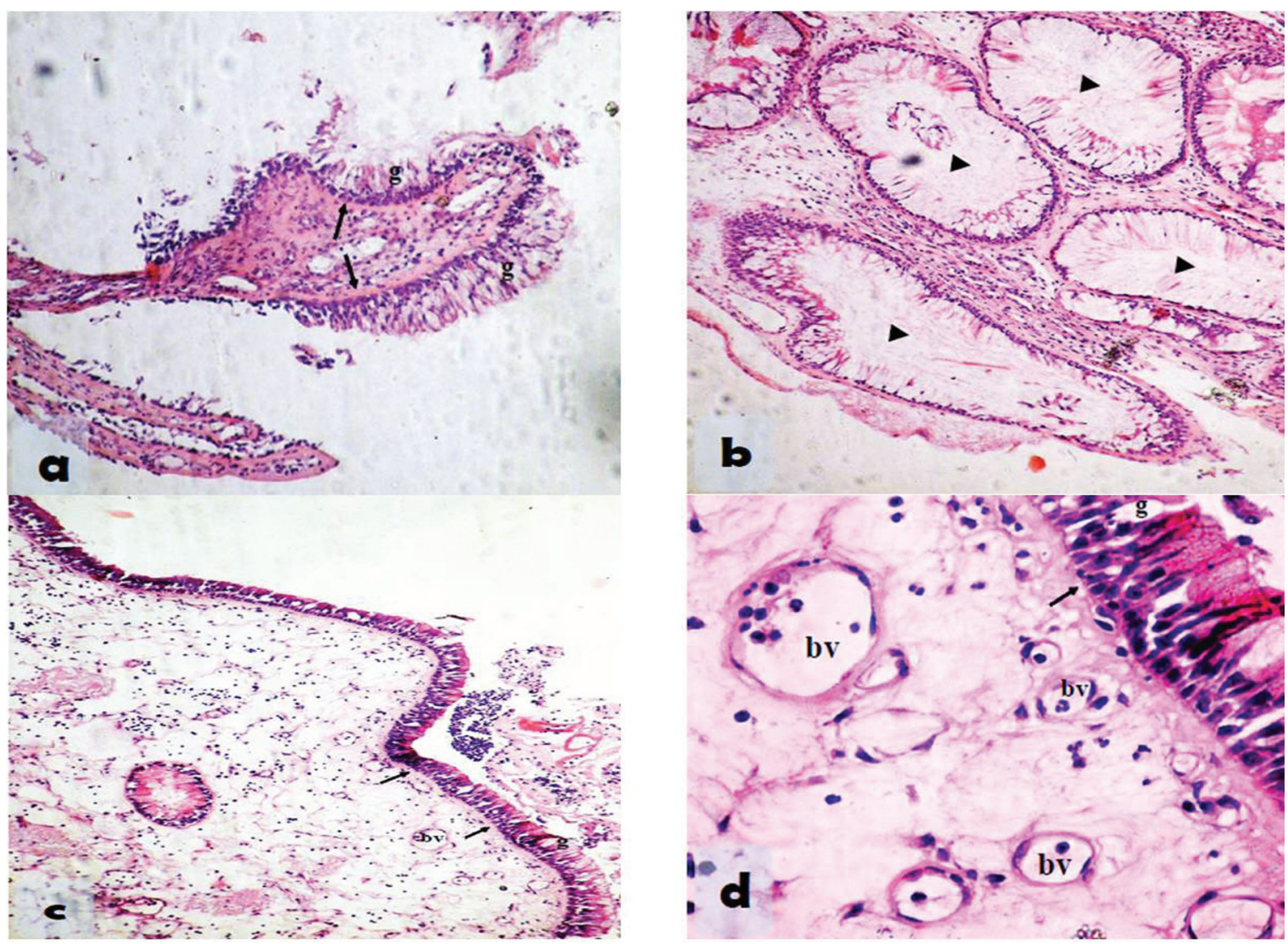

One-month postoperative case shows: $(a, b)$ Merocel packed side shows hyperplastic respiratory epithelium with thickened basal lamina $(\uparrow)$ and numerous goblet cells (g). The propria shows mild angiogenesis $\left(^{*}\right)$ and stimulated glandular activities (?). (c, d) Surgicel packed side shows classical respiratory epithelium with goblet cells $(\mathrm{g})$ resting on slightly thickened basal lamina $(\uparrow)$. The lamina propria shows edema with moderate angiogenesis (bv). Hematoxylin and eosin stain Mic. magnification, a, b, c, x100; $d$ and inset, $\times 400$.

Immediate postoperative assessment of patient bleeding and discomfort was assessed for Merocel packed sides and biodegradable material packed sides of all patients at day 1 and 2 postoperatively. Although the risk of significant hemorrhage following FESS is quite small, this can be a source of significant anxiety for the patient and has been shown to negatively influence the overall sense of recovery from the procedure [14].

In the present study, postoperative bleeding was significantly higher in the nondegradable packing side than the biodegradable side $(P<0.001)$ (Table 4$)$. The better hemostatic effect of biodegradable materials is consistent with the results reported by Stankiewicz [15] who compared Floseal with Merocel and reported significantly higher post-FESS epistaxis in the Merocel than Floseal sides [15]. Also, Kim et al. [16] observed that only $18.8 \%$ of those packed with biodegradable synthetic polyurethane foam following FESS had epistaxis compared with $81 \%$ of a Merocel group. On the other side, Lu and Zhang [17] found that there was no significant difference between Merocel and biodegradable nasal packing regarding postoperative bleeding. Also, Saedi et al. [18] stated that there was no significant difference between Merocel and no packing regarding hemostasis. This may be due to the difference in the used biodegradable materials as most of the biodegradable materials used in this study were medicated to be hemostatic (e.g. Surgiflo, Stammberger's Sinu-Foam, and Surgicel). A prospective, double-blind, randomized trial of 30 consecutive adults done by Shoman et al. [19] compared Nasopore with Merocel placed in a vinyl glove finger and found no significant difference between Merocel and biodegradable Nasopore regarding postoperative hemostasis. In another study, Cho et al. [20] compared Merocel with biodegradable Cutanplast and found that Merocel was associated with significantly more bleeding on removal with much time needed to control hemorrhage. Bleeding upon removal of nasal packing is a source of anxiety for the patient. This was managed perfectly using biodegradable materials in which there was no need for packing removal. In the present study, no bleeding upon pack removal was reported as the biodegradable materials have undergone complete biodegradation with no packing removal. Even with biodegradable packing removal 


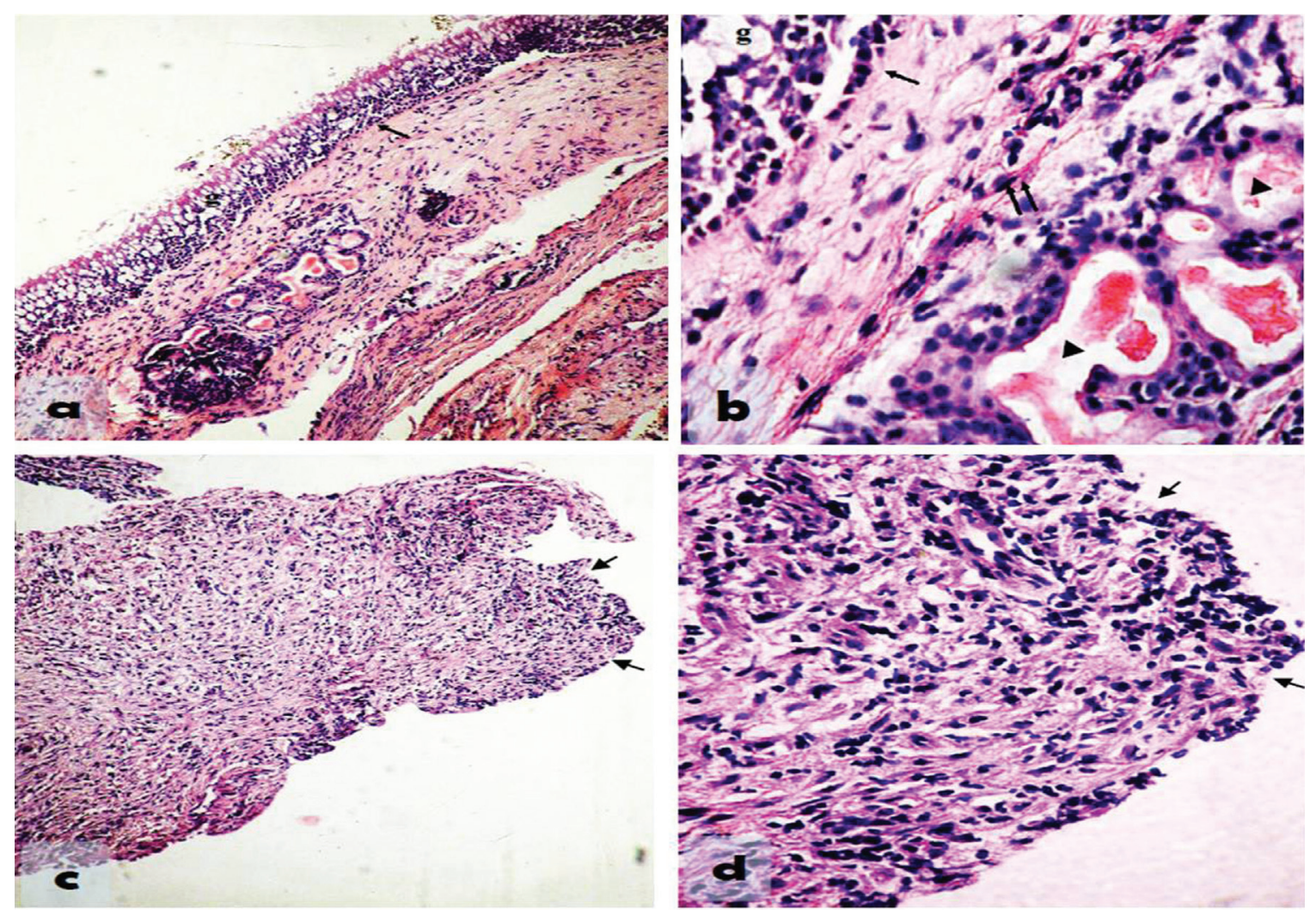

One-month postoperative case shows: $(a, b)$ Merocel packed side with hyperplastic respiratory epithelium with numerous goblet cells $(\mathrm{g})$ resting on thickened basal lamina ( $\uparrow$ ). The lamina propria showed excessive fibroblast $(\uparrow \uparrow)$ and excessive glandular activities (?). (c, d) Surgiflo packed side with defective epithelial covering $(\uparrow)$. The lamina propria shows excessive fibroblastic activities with mononuclear cellular infiltration. Hematoxylin and eosin stain Mic. magnification, $a$ and c, $\times 100$; b and d, $\times 400$.

Qian et al. [21], Lu et al. [22], Kim et al. [16,23], and Shoman et al. [19] have reported that there is a significant difference in bleeding upon removal between the Merocel and biodegradable sides.

Regarding pain and nasal obstruction as a source of patient discomfort while packing in situ, the current study recorded a much less degree of discomfort in the biodegradable sides than the Merocel sides. The difference was statistically significant $(P<0.001)$. Merocel-associated discomfort was previously described by Lu and Zhang [17], who found that Merocel was associated with more pain when compared with absorbable packing. Confirming that Berlucchi et al. [24] compared Merocel with Merogel nasal packing and they found significantly better patient comfort in the Merogel group. The results of the present study are also consistent with the results reported by Wang et al. [9] who showed that Nasopore is superior to Merocel in regard to in-situ pain and pain with removal. In addition, Leunig et al. [7] found no statistically significant difference between the carboxymethylcellulose (CMC)-packed side and the unpacked side with regard to patient comfort.
Synechiae that might lead to failure of FESS has an incidence of $\sim 8 \%[25,26]$. Synechia in the middle meatus can block the normal mucociliary drainage pathway of the sinuses and lead to disease recurrence. Numerous techniques, including suture medialization, partial resection of the middle turbinate, and nasal packing in the middle meatus, have been used to prevent postoperative synechia formation. Nasal packing remains the most common procedure to prevent synechia formation. The current study showed no significant difference regarding synechia formation between the biodegradable and Merocel packing sides at first and second visits ( $P>0.05$ for both visits). This is consistent with the results reported by Miller et al. [27] that conducted a blinded, randomized, controlled trial to compare the effects of biodegradable Merogel and Merocel packing in 37 patients who had undergone ESS. They found that the rate of synechia formation in both groups at 8 weeks after the operation was $~ 8 \%$, and the intergroup difference was not statistically significant. In a recent systemic review and meta-analysis, Wang et al. [28] showed that the biodegradable nasal packing was not associated with a significantly lower risk of synechia 


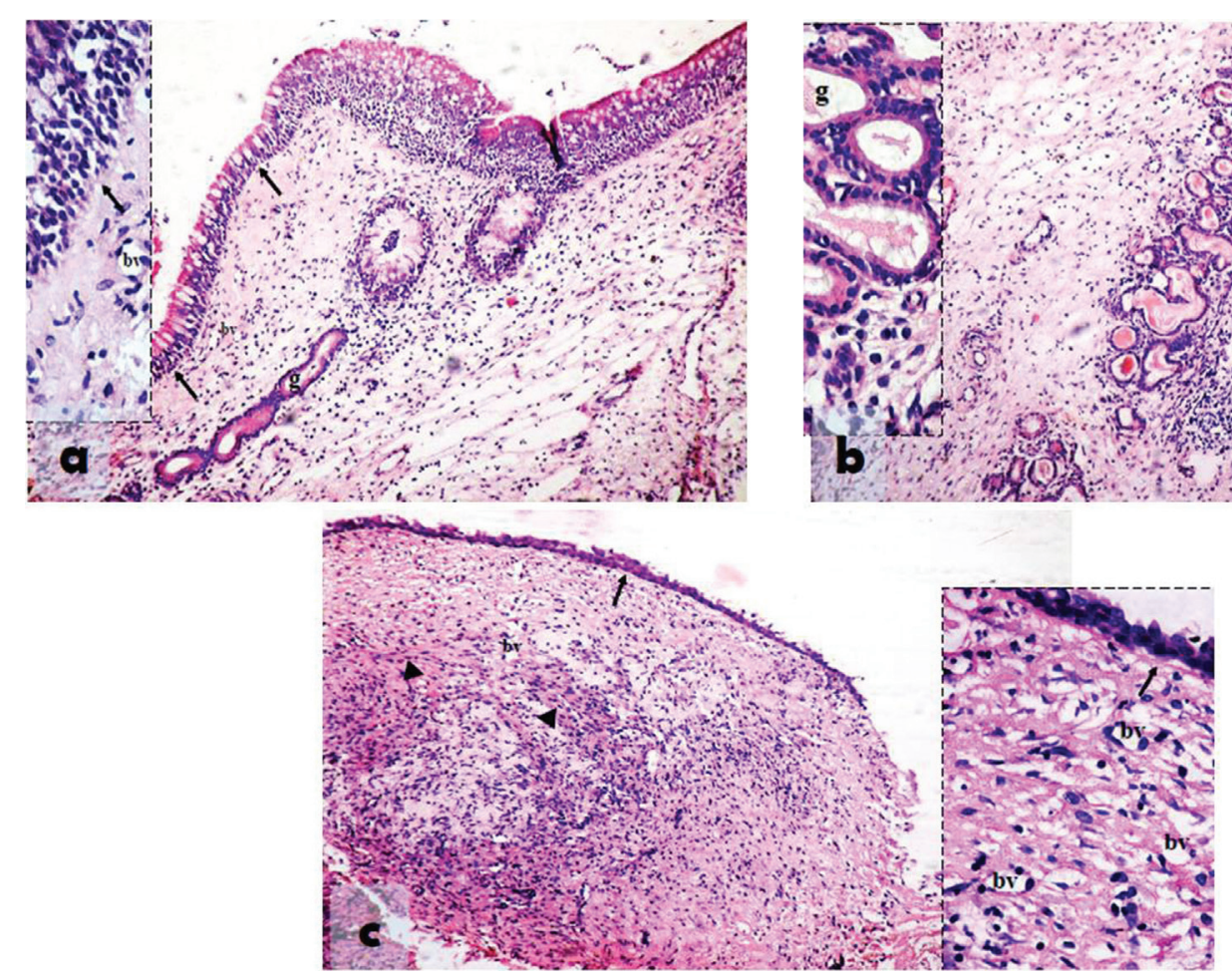

One-month postoperative case shows: $(a, b)$ Merocel packed side with hyperplastic respiratory epithelium with numerous goblet cells resting on thickened basal lamina ( $\uparrow$ ). The lamina propria shows newly formed blood vessels (bv) and hyperproliferated glands with increased activity (g). (c) Stammberger's Sinu-Foam packed side shows defective epithelial restoration resting on thin basal lamina ( $\uparrow$ ). The lamina propria shows subepithelial marked angiogenesis activity (bv). Increased fibroblastic (?) activity and cellular infiltration are also noticed. Hematoxylin and eosin stain Mic. magnification, $a, b$, and $c, \times 100$; insets in $a, b$, and $c, \times 400$.

after FESS for CRS compared with nondegradable nasal packing. However, $\mathrm{Hu}$ et al. [3] found that there was a reduced rate of postoperative synechia among patients who received biodegradable nasal packing compared with those who received no packing. In contrast, in a prospective, nonrandomized study, Baumann et al. [25] showed that there was a little difference in the rate of postoperative synechia between patients who received biodegradable Floseal and Merocel nasal packing. Several other studies have also failed to demonstrate any benefit of packing with biodegradable packing compared with no packing or nondegradable packing for reducing postoperative synechia $[7,21]$.

Sinonasal mucosal edema after FESS is an inevitable event that reflects the degree of operative trauma to nasal mucosa and the underlying inflammatory process. This edema can cause temporary obstruction to sinus ostia with consequent persistence of preoperative sinus symptoms. So, we may need postoperative local and sometimes systemic steroids to minimize such edema. The degree of this edema varies with the use of the different packing materials whether biodegradable and nondegradable. In the current study, endoscopic assessment at 1- and 3-month postoperatively showed that mucosal edema was significantly higher in biodegradable sides than nondegradable sides in both visits. This edema could be due to the interaction and contact between the nasal mucosa and biodegradable materials for longer time than that of the Merocel sides from which the Merocel was removed within 2-3 days. This result was against the results reported by $\mathrm{Lu}$ and Zhang [17] who compared the packing efficacy of Merocel with biodegradable (AquacelAg) in 24 patients after ESS and they found no statistically significant difference between the two groups regarding mucosal edema. Also, Wormald et al. [26] found no statistically significant difference between the Merogel packed side and the unpacked side regarding mucosal edema. Wee et al. [29] concluded that there was no statistically significant difference between the Gelfoam packed side and the unpacked side regarding mucosal edema.

The present study showed no statistically significant difference between the biodegradable and nondegradable sides regarding crustation and granulation tissue formation at 1- and 3-month postoperatively. These results were consistent with the results of Antisdel et al. [30] in their comparison 

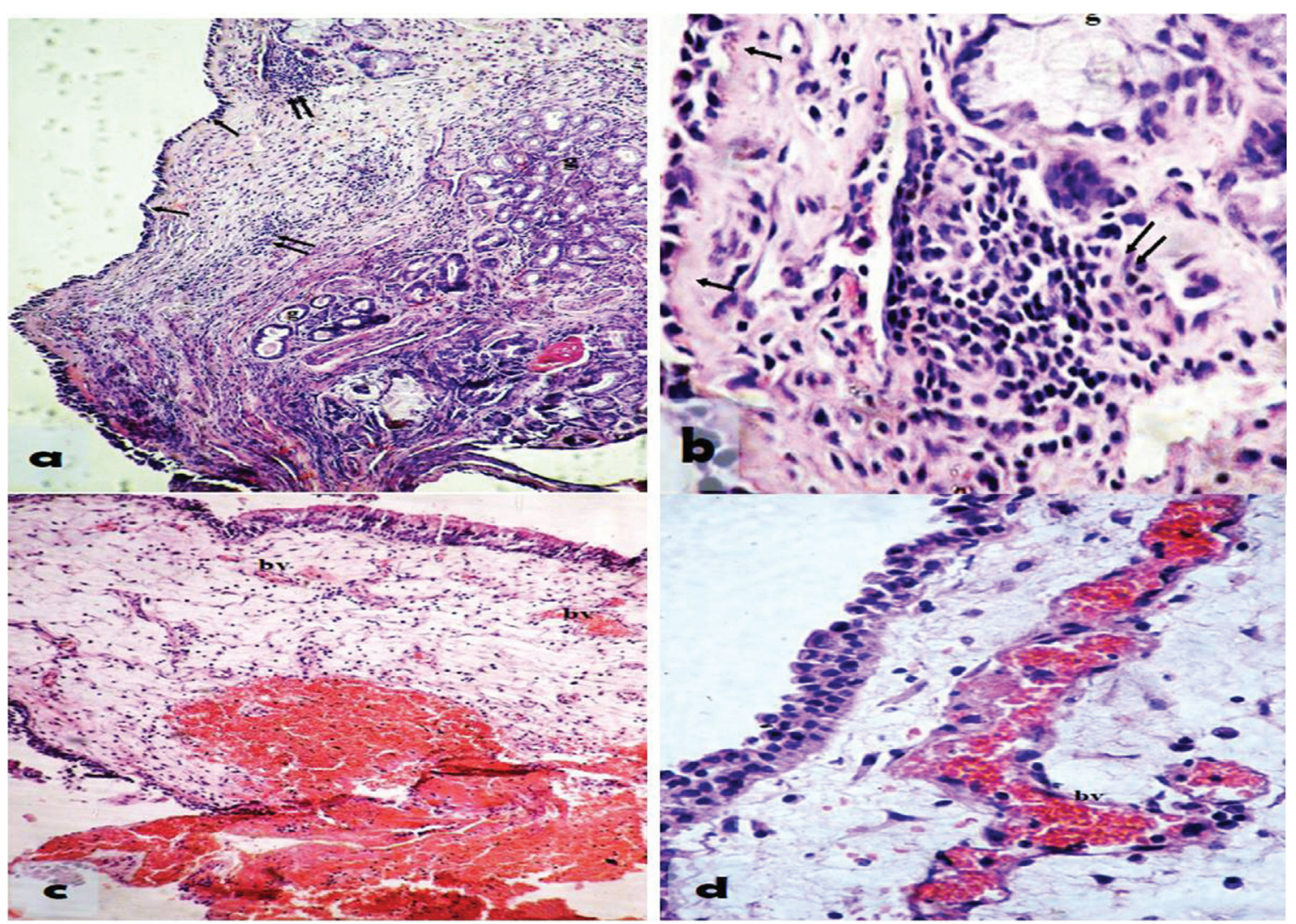

One-month postoperative case shows: $(a, b)$ Merocel packed side revealing respiratory epithelium resting on thickened basal lamina $(\uparrow)$ and excessive cellular infiltration ( $\uparrow$ ) and hyperglandular activities (g). (c, d) Gelfoam packed side with restored respiratory epithelium resting on thin basal lamina. The lamina propria shows edema and congested blood vessels (bv). Hematoxylin and eosin stain Mic. magnification, a and c, $\times 100 ; b$ and $d, \times 400$.

and equivalency analysis of three plant-based absorbable hemostatic agents (CMC gel, mucopolysaccharide hemispheres, and potato starch wafer). They found no statistical difference in the subjective level, but objective measures showed equivalency between all products, except the CMC gel approached significance at week 3 for increased crusting $(P=0.10)$. Also, Hu et al. [3] and Wee et al. [29] concluded that there was no difference in granulation between groups $(P=0.05)$.

Regarding the histopathologic part in the current study, we compared the effect of different biodegradable materials with Merocel on histopathological basis. Sinonasal mucosal biopsies were taken from our patients at 1- and 3-month postoperatively for histopathological examination using hematoxylin and eosin. This study revealed no statistically significant difference between biodegradable and nondegradable packing sides regarding the inflammatory cellular population in 1 month, but it turned statistically significant 3-month postoperatively. In respect to the effect on the epithelium of the sinonasal mucosa, this study showed better epithelial restoration with marked epithelial hyperplastic changes and more goblet cell in the Merocel sides than the biodegradable sides. This difference was statistically significant 1-month postoperatively, but turned nonsignificant at 3-month postoperatively. Basement membrane showed no statistically significant difference between the biodegradable and nondegradable sides. Furthermore, no signs of epithelial hyperplasia were seen neither in biodegradable nor in nondegradable sides.

On assessing the condition of stroma of the sinonasal mucosa, edema was significantly more evident in the biodegradable sides than the nondegradable sides both at 1- and at 3-month postoperatively. Regarding the subepithelial glandular activity, despite the more activity seen in the nondegradable sides, no statistically significant difference was found between the biodegradable and nondegradable sides at 1- and 3month postoperatively. The formation of new blood vessels was significantly more in the biodegradable than in the nondegradable sides at 1-month postoperatively, but it turned nonsignificant at 3-month postoperatively. No foreign body giant cells were noted in neither biodegradable nor nondegradable 


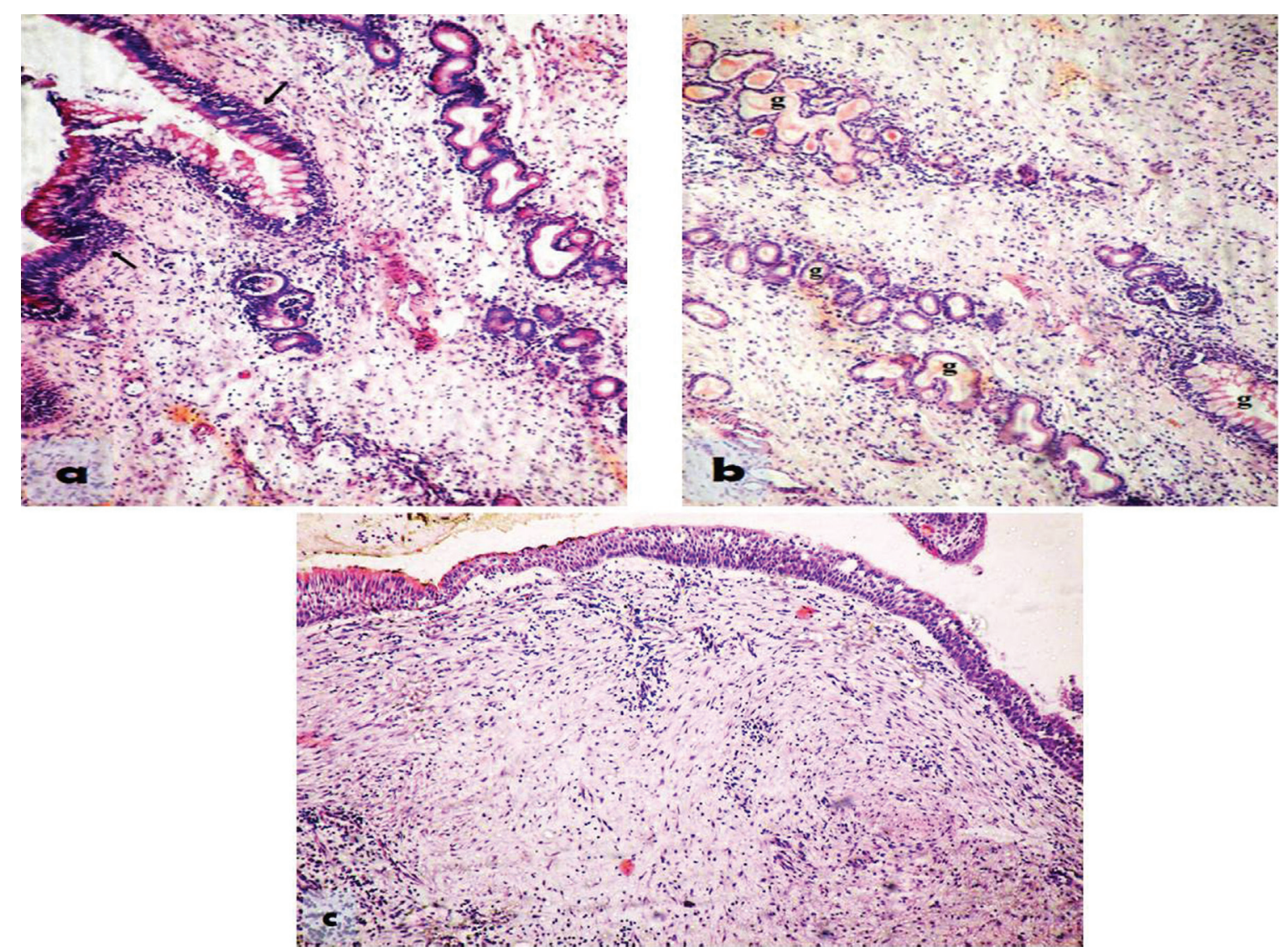

Three-month postoperative case shows: (a, b) Merocel packed nasal side with classical respiratory epithelium resting on thin basal lamina $(\uparrow)$. The lamina propria depicts excessive glandular activities (g) and mild inflammatory reaction. (c) Surgiflo packed nasal side with nearly normal structure and limited glandular activity. Mild inflammatory reaction is still noticed. Magnification $\times 100$.

sides at 1 - and 3-month postoperatively. Up to the current date, nearly all publications evaluating the histopathologic effect of different types of nasal packs on sinonasal mucosa postoperatively used animal models. In the literature, sheep have been shown to develop a similar spectrum of diseases to humans including sinusitis, nasal polyposis, and allergic rhinitis. In addition, the nasal cavity is suitable for nasal endoscopy and surgery [31].

McIntosh et al. [31] evaluated the effect of Merocel versus no packing on healing of sinonasal mucosal wounds in sheep with serial biopsies at 28 days interval up to 112 days. They found that there was no significant difference in the rate of reepithelialization between the packed and control sides of the sheep. There was no significant difference in the total amount of surface cilia coverage between the packed and control sides at any time points. There was no significant difference in the maturity of the cilia between the packed and control sides at any time points. Maccabee et al. [32] investigated the effect of topical Merocel and Floseal versus unpacked controls on paranasal sinus mucosal healing on the histopathological basis in a rabbit model. This study revealed that Merocel-treated mucosa showed extensive fibrosis of the basal lamina and lamina propria, complete loss of surface epithelium, and loss of the mucociliary blanket. Minimal resorption of the Merocel was found and Merocel fibers were frankly incorporated into the regenerated epithelium, associated with an exuberant lymphocytic infiltrate. Floseal-treated mucosa showed similar fibrosis of the basal lamina and lamina propria with loss of the mucociliary blanket, although to a lesser degree than the Merocel-treated group. Floseal showed similar incorporation into the healed mucosa with lymphocytosis. Controls showed expected submucosal gland reduction, lamina propria fibrosis, and loss of cilia, but the lamina propria fibrosis seen in the Merocel and Floseal groups was markedly more prominent.

\section{Conclusions}

Biodegradable nasal packing can offer patients a good quality of life during the early recovery period, which is significantly better than nondegradable nasal packing. 
However, no beneficial or detrimental effects on postoperative mucosal healing were noted for variable mucosal edema. On the other hand, especially in the early postoperative period, nondegradable packs like Merocel can offer less post-FESS edema providing better aeration and rapid epithelial restoration, and hence faster wound healing.

\section{Financial support and sponsorship}

Nil.

\section{Conflicts of interest}

There are no conflicts of interest.

\section{References}

1 Zhao X, Grewal A, Briel M, Lee JM. A systematic review of nonabsorbable absorbable, and steroid-impregnated spacers following endoscopic sinus surgery. Int Forum Allergy Rhinol 2013; 3:896-904.

2 Chang EH, Alandejani T, Akbari E, Ostry A, Javer A. Double-blinded, randomized, controlled trial of medicated versus nonmedicated meroce sponges for functional endoscopic sinus surgery. J Otolaryngol Head Neck Surg 2011; 40 (Suppl 1):S14- S19.

$3 \mathrm{Hu} \mathrm{KH}$, Lin KN, Li WT, Huang HM. Effects of Meropack in the middle meatus after functional endoscopic sinus surgery in children with chronic sinusitis. Int J Pediatr Otorhinolaryngol 2008; 72:1535-1540.

4 Hesham A, Fathi A, Attia M, Safwat S, Hesham A. Laser and topical mitomycin $\mathrm{C}$ for management of nasal synechia after FESS: a preliminary report. Eur Arch Otorhinolaryngol 2011; 268:1289-1292.

5 Valentine R, Wormald PJ, Sindwani R. Advances in absorbable biomaterials and nasal packing. Otolaryngol Clin North Am 2009; 42:813-828, ix.

6 Verim A, Seneldir L, Naiboglu B, Karaca CT, Kulekci S, Toros SZ, et al. Role of nasal packing in surgical outcome for chronic rhinosinusitis with polyposis. Laryngoscope 2014; 124:1529-1535.

7 Leunig A, Betz CS, Siedek V, Kastl KG. CMC packing in functional endoscopic sinus surgery: does it affect patient comfort? Rhinology 2009; 47:36-40.

8 Stevens RW. Nasal packing; the rubber pneumatic pack. AMA Arch Otolaryngol 1951; 54:191-194.

9 Wang J, Cai C, Wang S. Merocel versus Nasopore for nasal packing: a meta-analysis of randomized controlled trials. PLoS One 2014; 9:e93959.

10 Taasan V, Wynne JW, Cassisi N, Block AJ. The effect of nasal packing on sleep-disordered breathing and nocturnal oxygen desaturation. Laryngoscope 1981; 91:1163-1172.

11 Yan M, Zheng D, Li Y, Zheng Q, Chen J, Yang B. Biodegradable nasal packings for endoscopic sinonasal surgery: a systematic review and metaanalysis. PLoS One 2014; 9:e115458.

12 McIntosh D, Cowin A, Adams D, Rayner T, Wormald PJ. The effect of a dissolvable hyaluronic acid-based pack on the healing of the nasal mucosa of sheep. Am J Rhinol 2002; 16:85-90.

13 Rajapaksa SP, Cowin A, Adams D, Wormald PJ. The effect of a hyaluronic acid-based nasal pack on mucosal healing in a sheep model of sinusitis. Am J Rhinol 2005; 19:572-576.

14 Wang YP, Wang MC, Chen YC, Leu YS, Lin HC, Lee KS. The effects of Vaseline gauze strip, Merocel, and Nasopore on the formation of synechiae and excessive granulation tissue in the middle meatus and the incidence of major postoperative bleeding after endoscopic sinus surgery. J Chin Med Assoc 2011; 74:16-21.
15 Stankiewicz JA. Complications of endoscopic sinus surgery. Otolaryngol Clin North Am 1989; 22:749-758.

16 Kim YS, Kim YH, Kim NH, Kim SH, Kim KR, Kim KS. A prospective, randomized, single-blinded controlled trial on biodegradable synthetic polyurethane foam as a packing material after septoplasty. Am J Rhinol Allergy 2011; 25:e77-e79.

$17 \mathrm{Lu} \mathrm{H}$, Zhang $\mathrm{X}$. AquacelAg used in nasal packing after endoscopic sinus surgery. Lin Chuang Er Bi Yan Hou Ke Za Zhi 2005; 19:1059-1060.

18 Saedi B, Sadeghi M, Farschi S. Effect of polyvinyl acetal sponge nasal packing on post-operative care of nasal polyposis patients: a randomised, controlled, partly blinded study. J Laryngol Otol 2012; 126:380-384

19 Shoman N, Gheriani H, Flamer D, Javer A. Prospective, double-blind, randomized trial evaluating patient satisfaction, bleeding, and wound healing using biodegradable synthetic polyurethane foam (NasoPore) as a middle meatal spacer in functional endoscopic sinus surgery. $J$ Otolaryngol Head Neck Surg 2009; 38:112-118.

20 Cho KS, Shin SK, Lee JH, Kim JY, Koo SK, Kim YW, et al. The efficacy of Cutanplast nasal packing after endoscopic sinus surgery: a prospective, randomized, controlled trial. Laryngoscope 2013; 123:564-568.

21 Qian D, Zhang HW, GAO CS, Yang Q, Li L. Clinical observation on the usability of NasoPore in functional endoscopic septoplasty. Chin Med Guide 2013; 2013:272-273.

22 Lu CMY, Dong BC, Zhang DX. Comparative observation on the clinical usability of biodegradable synthetic polyurethane foam and Merocel during functional endoscopic septoplasty. Chin J Otorhinolaryngol Integ Med 2013; 21:184-186.

$23 \mathrm{Kim} \mathrm{ST}$, Cho KB, Kang IG. Preventive effects of polyurethane foam and polyvinyl acetate on bleeding and pain in young patients undergoing conchotomies. Int J Pediatr Otorhinolaryngol 2013 77:113-116.

24 Berlucchi M, Castelnuovo P, Vincenzi A, Morra B, Pasquini E. Endoscopic outcomes of resorbable nasal packing after functional endoscopic sinus surgery: a multicenter prospective randomized controlled study. Eur Arch Otorhinolaryngol 2009; 266:839-845.

25 Baumann A, Caversaccio M. Hemostasis in endoscopic sinus surgery using a specific gelatin-thrombin based agent (FloSeal). Rhinology 2003; 41:244-249.

26 Wormald PJ, Boustred RN, Le T, Hawke L, Sacks R. A prospective singleblind randomized controlled study of use of hyaluronic acid nasal packs in patients after endoscopic sinus surgery. Am J Rhinol 2006; 20:7-10.

27 Miller RS, Steward DL, Tami TA, Sillars MJ, Seiden AM, Shete M, et al. The clinical effects of hyaluronic acid ester nasal dressing (Merogel) on intranasal wound healing after functional endoscopic sinus surgery. Otolaryngol Head Neck Surg 2003; 128:862-869.

28 Wang TC, Tai CJ, Tsou YA, Tsai LT, Li YF, Tsai MH. Absorbable and nonabsorbable packing after functional endoscopic sinus surgery: systematic review and meta-analysis of outcomes. Eur Arch Otorhinolaryngol 2015; 272:1825-1831.

29 Wee JH, Lee CH, Rhee CS, Kim JW. Comparison between Gelfoam packing and no packing after endoscopic sinus surgery in the same patients. Eur Arch Otorhinolaryngol 2012; 269:897-903.

30 Antisdel JL, Meyer A, Comer B, Jang D, Gurrola J, Khabbaz E, et al. Product comparison model in otolaryngology: equivalency analysis of absorbable hemostatic agents after endoscopic sinus surgery. Laryngoscope 2016; 126 (Suppl 2):S5- S13.

31 McIntosh D, Cowin A, Adams D, Wormald PJ. The effect of an expandable polyvinyl acetate (Merocel) pack on the healing of the nasal mucosa of sheep. Am J Rhinol 2005; 19:577-581.

32 Maccabee MS, Trune DR, Hwang PH. Effects of topically applied biomaterials on paranasal sinus mucosal healing. Am J Rhinol 2003, 17:203-207. 